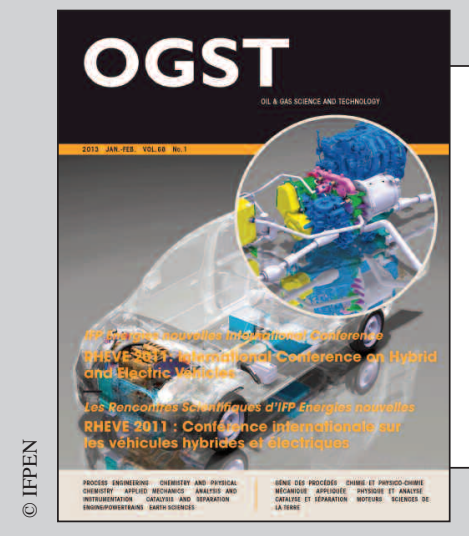

Dossier

This paper is a part of the hereunder thematic dossier published in OGST Journal, Vol. 68, No. 1, pp. 3-178 and available online here

Cet article fait partie du dossier thématique ci-dessous publié dans la revue OGST, Vol. 68, n 1 , pp. 3-178 et téléchargeable ici

DOSSIER Edited by/Sous la direction de : A. Sciarretta, F. Badin et J. Bernard RHEVE 2011 : International Conference on Hybrid and Electric Vehicles RHEVE 2011 : Conférence internationale sur les véhicules hybrides et électriques

Oil \& Gas Science and Technology - Rev. IFP Energies nouvelles, Vol. 68 (2013), No. 1, pp. 3-178

Copyright (C) 2013, IFP Energies nouvelles

\section{$3>$ Editorial}

$13>$ Analysis and Experimental Implementation of a Heuristic Strategy for Onboard Energy Management of a Hybrid Solar Vehicle

Analyse et expérimentation d'une stratégie heuristique pour la gestion d'énergie à bord d'un véhicule hybride solaire

G. Coraggio, C. Pisanti, G. Rizzo and M. Sorrentino

23 > Open Issues in Supervisory Control of Hybrid Electric Vehicles: A Unified Approach Using Optimal Control Methods

Questions ouvertes sur la supervision énergétique des véhicules hybrides électriques : une approche unifiée par la théorie de la commande optimale

L. Serrao, A. Sciarretta, 0. Grondin, A. Chasse, Y. Creff, D. Di Domenico, P. Pognant-Gros, C. Querel and L. Thibault

35 > Optimization of Hybrid Power Trains by Mechanistic System Simulations

Optimisation de groupes motopropulseurs électriques hybrides par simulation du système mécanique

T. Katrašnik and J.C. Wurzenberger

51 > A Phenomenological Heat Transfer Model of SI Engines - Application to the Simulation of a Full-Hybrid Vehicle

Un modèle phénoménologique de transfert thermique au sein de moteurs à allumage commandé - Application à la simulation d'un véhicule full-hybride

R. Dubouil, J.-F. Hetet and A. Maiboom

$65>$ Battery Electric Vehicle (BEV) or Range Extended Electric Vehicle (REEV)? - Deciding Between Different Alternative Drives Based on Measured Individual Operational Profiles

Véhicule électrique à batteries (BEV) ou véhicule électrique à prolongateur d'autonomie (REEV) ? - Choisir entre différents entrânements alternatifs sur la base de profils opérationnels individuels mesurés

S. Marker, B. Rippel, P. Waldowski, A. Schulz and V. Schindler

$79>$ Assessment by Simulation of Benefi ts of New HEV Powertrain Configurations

Évaluation par simulation des bénéfi ces de nouvelles chaînes de traction hybrides

N. Kim and A. Rousseau
95 > Dual Mode Vehicle with In-Wheel Motor: Regenerative Braking Optimization

Véhicule bi-mode avec moteurs roues : optimisation du freinage récupératif

G. Le Solliec, A. Chasse, J. Van-Frank and D. Walser

109 > Engine Downsizing and Electric Hybridization Under Consideration of Cost and Drivability

Réduction de taille moteur et hybridation électrique avec considérations de coût et de performance de conduite

S. Ebbesen, P. Elbert and L. Guzzella

117 > Representative Midwestern US Cycles: Synthesis and Applications Cycles représentatifs du Middle West américain : synthèse et applications

T.-K. Lee and Z.S. Filipi

127 > A Review of Approaches for the Design of Li-lon BMS Estimation Functions

Revue de différentes approches pour l'estimation de l'état de charge de batteries Li-ion

D. Di Domenico, Y. Creff, E. Prada, P. Duchêne, J. Bernard and V. Sauvant-Moynot

137 > Experimental Assessment of Battery Cycle Life Within the SIMSTOCK Research Program

Évaluation expérimentale de la durée de vie de la batterie dans le programme de recherche SIMSTOCK

P. Gyan, P. Aubret, J. Hafsaoui, F. Sellier, S. Bourlot, S. Zinola and F. Badin

$149>$ Smart Battery Thermal Management for PHEV Efficiency Une gestion avancée de la thermique de la batterie basse tension de traction pour optimiser l'efficacité d'un véhicule hybride électrique rechargeable

L. Lefebvre

$165>$ Parameterization and Observability Analysis of Scalable Battery Clusters for Onboard Thermal Management

Paramétrage et analyse d'observabilité de clusters de batteries de taille variable pour une gestion thermique embarquée

Xinfan Lin, Huan Fu, Hector E. Perez, Jason B. Siege, Anna G. Stefanopoulou, Yi Ding and Matthew P. Castanier 


\title{
A Review of Approaches for the Design of Li-lon BMS Estimation Functions
}

\author{
D. Di Domenico*, Y. Creff, E. Prada, P. Duchêne, J. Bernard and V. Sauvant-Moynot \\ IFP Energies nouvelles, Rond-point de l'échangeur de Solaize, BP 3, 69360 Solaize - France \\ e-mail: domenico.didomenico@ifpen.fr - yann.creff@ifpen.fr - eric.prada@ifpen.fr - pascal.duchene@ifpen.fr \\ julien.bernard@ifpen.fr - valerie.sauvant@ifpen.fr \\ *Corresponding author,
}

\begin{abstract}
Résumé - Revue de différentes approches pour l'estimation de l'état de charge de batteries Li-ion - Cet article vise à comparer différentes approches pour l'estimation de l'état de charge pour les batteries Li-ion. Les principaux avantages ainsi que les points critiques des différentes techniques sont analysés, en soulignant l'impact de la complexité et de la précision du modèle sur les performances de l'estimateur. La procédure complète, allant de la caractérisation de la cellule jusqu'à l'estimation en ligne de l'état de charge, est présentée pour la modélisation par circuit électrique équivalent. Les tests expérimentaux sur la base des données acquises au laboratoire batteries d'IFP Energies nouvelles montrent que cette stratégie permet d'obtenir un estimateur en temps réel de l'état de charge présentant de bonnes performances.
\end{abstract}

\begin{abstract}
A Review of Approaches for the Design of Li-Ion BMS Estimation Functions - This paper aims at comparing different approaches for the estimation of the state of charge of lithium-ion batteries. The main advantages as well as the critical points of the considered techniques are analyzed, highlighting the impact of the cell model precision and complexity on the estimator performance. Among others, the electrical equivalent circuit based technique is selected for further development. The results of a complete procedure from the cell characterization to the online estimation are illustrated. The experimental tests based on the data collected on batteries testing facilities of IFP Energies nouvelles show that the proposed strategy allows a satisfying state of charge real time estimation.
\end{abstract}

\section{INTRODUCTION}

The progressive increases in the oil costs as well as the emission restrictions imposed by the standards to reduce the environmental pollution are strongly stimulating the research interest for non-traditional vehicles. It is widely accepted that, among others, Electric, Hybrid Electric and Plug-in Hybrid Electric Vehicles (EV, HEV and PHEV) represent a promising alternative to traditional vehicles. Their massive presence and good performance in portable electric devices make lithium-ion (Li-ion) battery a natural candi- date for electrical energy source in the new vehicles concepts.

The automotive control research is then moving towards efficient Li-ion Battery Management System (BMS) design. BMS has to ensure the appropriate use of the capability of the battery in providing the electrical power demand while guaranteeing feasible and safe operations. Indeed, apart from avoiding the overcharge, the overdischarge and the thermal abuse, that can cause battery lifetime degradation, permanent damages or even explosion, an efficient BMS must include the cell monitoring, the cell balancing, the estimation functions and the battery thermal management. 
Among other factors, the battery State of Charge (SOC) has a big impact on the dynamics as well as on the battery behavior in terms of voltage, thermal increase and available power. Accurate knowledge of the actual battery SOC is thus required for the vehicle management, for achieving high efficiency, slow aging, no battery damaging and, for the HEV and the PHEV, for reducing the pollutant emission. Furthermore, as a reliable SOC estimation allows a correct use of the battery, it is useful to improve both battery health and vehicle economy through optimal battery sizing [1]

As a consequence, SOC estimation is a key task for BMS [2,3]. Several techniques have been proposed for SOC estimation, with advantages and disadvantages [4]. Among them, the Ampere-hour (Ah) counting is used by many industrial battery BMSs. Consisting in integrating the battery current, this open-loop and non-model based method is easy to implement online but it is affected by the uncertainty on the initial condition, by the measurement error accumulated during the battery life and by the battery capacity degradation due to usage $[3,5,6]$. To overcome these issues and improve the BMS functions, several approaches based on dynamic battery models have been investigated in $[4,5,7-19]$. Regarding the SOC estimation, the main advantage of the model-based methods is that the initialization error can be recovered by means of output (voltage and temperature) feedback, the closed-loop estimation concept consisting in comparing the measurement of the cell voltage and temperature with model predictions. In case of discordance, the state value is corrected in order to minimize the prediction mismatch. A further advantage of some modelbased estimators is to filter the measurement noise.

To take advantage of a model-based estimator, a high precision open-loop model of the cell is required, both for steady-state (open circuit voltage vs SOC map) and for dynamics (related to the model parametrization). At steady state, a variation of $80 \%$ of SOC implies a typical variation of the cell voltage smaller than $1 \mathrm{~V}$, so a low precision in voltage prediction leads to a huge indetermination in SOC. If a SOC error of a few percents is desired, the level of precision for the steady state voltage should be about $20 \mathrm{mV}$, this value depending on the specific application, chemistry and SOC range. For the cell dynamics modeling, no generalization can be made, because the required degree of precision depends on the operational conditions. Nevertheless, the model has to be able to accurately reproduce the measured voltage shape during usage.

For practical purposes the battery models can be classified in two main categories, the equivalent circuit and the electrochemical models. This paper presents a short review of the main models for both categories, critically oriented to the design of BMS for automotive application. Then a case study is proposed. It illustrates a comprehensive procedure for obtaining a cell inner state estimator, including the experimental characterization and the model calibration.
The proposed estimation strategy leans on both static and dynamic modeling approaches. The procedure effectiveness is tested by considering both the modeling and estimation aspects. An experimental test based on the data collected on batteries testing facilities of IFP Energies nouvelles shows that the proposed approach allows for a satisfying SOC real time estimation.

\section{AMPERE-HOUR COUNTING}

Ampere-hour counting can be considered as the classical SOC estimation technique and it is used by many commercial battery BMSs. Based on the relationship between the electric current and the electric charge, the SOC is defined as

$$
\operatorname{SOC}(t)=\operatorname{SOC}\left(t_{0}\right)+\frac{1}{C_{\text {nom }}} \int_{t_{0}}^{t} I_{\text {cell }}(\tau) d \tau
$$

where $I_{\text {cell }}$ is cell current and $C_{\text {nom }}$ is the nominal cell capacity. This open-loop and non-model based method is easy to implement online but it is affected by the uncertainty on the initial condition, by the measurement error accumulated during the battery life and by the battery capacity degradation with battery aging $[3,5,6]$. Other drawbacks, such as the losses during charge or discharge and the estimation drift caused by the cell self-discharge have also been highlighted [20]. The Ah counting can be combined with a closed-loop initialization technique: after a long rest period, the SOC estimation is updated by inverting the Open Circuit Voltage (OCV) map based on the voltage measurement [3].

In order to perform the initialization, an offline characterization of the OCV as function of the SOC and temperature is necessary. The precision of SOC estimation performed with the Ah counting method is essentially given by the derivative of the OCV with respect to the SOC and it depends on the actual SOC value. Moreover several factors, such as the voltage sensor accuracy, the measurement errors or the statistical dispersion among the cells can strongly affect the precision of the map and, as a consequence, the precision of the SOC initialization. The error on SOC initialization is then propagated with time, invalidating the estimation. Furthermore, due to the large characteristic time associated to the battery relaxation, the OCV measurement can be unavailable in automotive applications $[11,19]$. It is also worth noting that such a map-based model is useless for power estimation as it can not predict the cell voltage during the non-zero current demands.

\section{EQUIVALENT CIRCUIT MODELS}

Equivalent circuit models are based on the equivalence between electrochemical impedance and electric impedance. The model calibration is usually performed by means of the Electrochemical Impedance Spectroscopy 
(EIS), that consists in experimentally collecting the response of the battery to a low-amplitude alternating current signal, for a wide range of frequencies. Impedance-based models tend to represent the three main $\mathrm{Li}$-ion electrochemical phenomena, each being preponderant in a typical range of frequencies: electro-migration inside the electrolyte and connectors (at high frequencies), Butler-Volmer electrochemical charge transfer kinetics associated with electrochemical double layer capacity (at medium frequencies) and diffusion of ionic species in the electrodes and in the electrolyte (at low frequencies). An electric circuit can be inferred from the electrochemical spectrum.

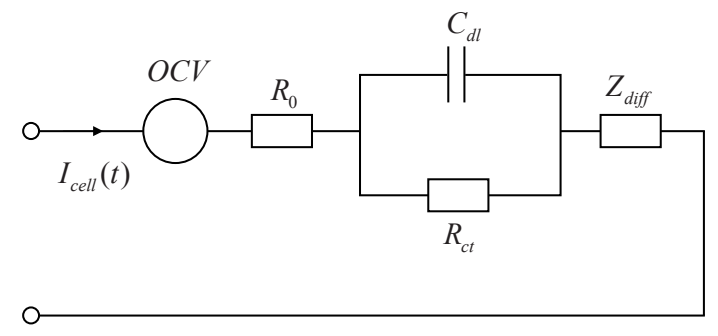

Figure 1

Modified Randles scheme.

Figure 1 shows an usual electric equivalent scheme. High frequency effects are reproduced by the resistor $R_{0}$, medium frequency effects by the resistor-capacitance circuit and low frequency effects by the diffusion impedance $Z_{\text {diff }}$. The parameters of the resistor-capacitance circuit can be related to the electrochemical charge transfer kinetics. From a simplified Butler-Volmer formalism for a redox reaction, the charge transfer current density can be expressed as:

$$
i_{f}=i_{0}\left(\exp \left(\frac{\alpha_{o x} n F}{R_{g} T} \eta\right)-\exp \left(-\frac{\alpha_{\text {red }} n F}{R_{g} T} \eta\right)\right)
$$

with $\alpha_{o x}$ and $\alpha_{\text {red }}$ the oxidation and reduction charge transfer coefficients, $n$ the number of electrons transferred by the reaction, $\eta$ the overpotential, obtained as the difference between the electrode potential and the equilibrium potential, $F$ the Faraday's constant, $R_{g}$ the universal gas constant, $T$ the cell temperature and $i_{0}$ the exchange current density. The exchange current density may depend on the value of solid concentration but it is usually, in particular in the equivalent circuit approach, considered as a constant. A symmetry assumption $\left(\alpha_{r e d}=\alpha_{o x}=0.5\right)$ is made concerning the charge and discharge, giving charge transfer resistance $R_{c t}$ as a function of $i_{f}$. The charge transfer current can be then approximated by $I_{\text {cell }} / A$, where $A$ is the equivalent electro-active surface, which depends on the electrodes design parameters. These assumptions give:

$$
R_{c t}=\left(\frac{\partial i_{f}}{\partial \eta}\right)^{-1}=\frac{R_{g} T}{i_{0} n F \sqrt{1+\left(\frac{I_{\text {cell }}}{2 i_{0} A}\right)^{2}}}
$$

The double layer capacity $C_{d l}$ can be related to the electrochemical cell properties [21] but it is in general identified based on the experimental spectra. Several choices are possible for the diffusion impedance $Z_{\text {diff }}$ in Figure 1. One of the most frequent choice is to represent the diffusive impedance by a Warburg impedance, the expression of which differs as the mass transport boundary conditions vary [22]. Under the assumption of a finite-length diffusion, the diffusion impedance can be written as:

$$
Z_{\text {diff }}(s)=R_{d} \frac{\tanh \sqrt{s \tau_{D}}}{\sqrt{s \tau_{D}}}
$$

with $R_{d}$ the diffusion resistor, $\tau_{D}$ the characteristic diffusion time of the phenomenon and $s$ the Laplace variable. An infinite-length diffusion hypothesis gives:

$$
Z_{\text {diff }}(s)=R_{d} \frac{\operatorname{coth} \sqrt{s \tau_{D}}}{\sqrt{s \tau_{D}}}
$$

If a semi-infinite diffusive layer is considered, $Z_{\text {diff }}$ becomes:

$$
Z_{\text {diff }}(s)=\sigma \frac{1}{s^{0.5}}
$$

where $\sigma$ is a real constant. Equation (6) represents a particular case of a Constant Phase Element (CPE). The CPE was introduced by Cole and Cole [23] and is associated to a number of phenomena, such as a porous electrode or a slow anion adsorption. It has been proposed for representing the diffusion impedance for some Li-ion models [24,25]. This choice corresponds to:

$$
Z_{\text {diff }}(s)=\frac{1}{Q s^{\alpha}}
$$

where $Q$ is a generalized capacity and $0<\alpha<1$ is a depression factor. Some authors also proposed a parallel diffusive electric assembly of a CPE and a diffusion resistance $R$ [24], corresponding to the impedance:

$$
Z_{\text {diff }}(s)=\frac{1}{1 / R+Q s^{\alpha}}
$$

For a given cell, the impedance is a global result of several combined properties, including also the experimental test set-up, i.e. the amplitude of the frequencies interval of the EIS and the operating conditions. As a consequence, the choice of $Z_{\text {diff }}$ is performed, from a practical point of view, on the basis of the observed experimental spectra.

In order to use one of the above impedances (Eq. 4-8) for BMS application, the transposition to the time-domain 
is required. The Warburg impedance for finite diffusion in Equation (4), for example, is usually implemented as a transmission line by a finite-length Cauer or Foster-type electric network [26].

From a theoretical point of view, the impedance-based modeling technique is equivalent to a system linearization around an equilibrium point at zero input and can rigorously be applied only for low demanded currents, i.e. for small state variations. Nevertheless, BMS applications of equivalent circuit model have often been presented [19, 27-30]. Classically, the equivalent circuit battery models were used in BMS for portable electronics, where the approximation is adequate. This modeling approach has then been extended to automotive applications. But care has to be taken because of high current pulses that are out of the model range of application. In order to adapt equivalent circuit models to automotive applications, a circuit parameters dependence on SOC [29-31], temperature and the amplitude of applied current can be fitted. Moreover, to reach the precision required for BMS applications, it may be necessary to use a more complex electric network than the one shown in Figure 1. As highlighted in [2], increasing the model complexity leads to a model with a number of parameters which is comparable to the electrochemical model. But these parameters have no physical meaning, in particular for the description of the low frequencies diffusive phenomena. Nevertheless, the validation tests for these complex equivalent circuit models give good results in general. The average absolute error may vary, depending on the cycling test and the operating conditions.

In general, the results presented in the literature show that a model error between $20 \mathrm{mV}$ and $30 \mathrm{mV}$ results in an error on the SOC estimation of a few percents $[9,24,32,33]$.

\section{ELECTROCHEMICAL MODELS}

Several electrochemical models of batteries have been proposed, with varying degrees of complexity. The first electrochemical approach for modeling the electrodes porosity was presented by Newman and Tiedemann [34]. The electrode is treated as a superposition of two continua, namely the electrolytic solution and the solid matrix. The solid matrix is modeled as microscopic spherical particles, in which the active specie diffuses and on the surface of which it reacts. Based on this approach, Wang et al. introduced [35] a pseudo 2-dimensional model of a cell that incorporates solid-state physics and interface chemistry and, which can be adapted to a wide range of active materials and electrolyte solutions. First presented for Ni-MH batteries [36], it was then extended to lithium-ion batteries $[37,38]$, where the thermal behavior was also described. Based on this model, Ramadass et al. [39] accounted for the decay in capacity of the cell and for the increase of the resistance due the Solid Electrolyte Interphase (SEI) growth. The pseudo-2D electrochemical models predict the dynamic profile of solid concentration in the solid phase across the electrode, i.e. the $x$-dimension distribution of the lithium concentration.

Simplified 1D electrochemical models versions of this approach have also been presented, either by removing the radial dimension, [40], or by neglecting the $x$-dimension variations with an averaging procedure in [2,41-43].

For both the pseudo-2D and 1D models the most relevant equation for SOC observers design purpose is the Fick's equation, describing the solid concentrations diffusion:

$$
\frac{\partial c_{s}}{\partial t}=\vec{\nabla}\left(D_{s} \vec{\nabla} c_{s}\right)
$$

where $c_{s}$ is the concentration of the active material and $D_{s}$ is the diffusion coefficient of the inserted species. For sake of conciseness, the complete set of equations governing the pseudo-2D model is not reported here. It can be found, for instance, in [18]. Written in the radial dimension for describing the diffusion of the active species in the spherical particles of radius $R_{s}$, the Fick equation is:

$$
\frac{\partial c_{s}}{\partial t}=D_{s}\left(\frac{\partial^{2} c_{s}}{\partial r^{2}}+\frac{2}{r} \frac{\partial c_{s}}{\partial r}\right)
$$

with boundary conditions connecting the concentration with the chemistry of the reactions through the Butler-Volmer microscopic current density $j^{\mathrm{Li}}$ :

$$
\left.\frac{\partial c_{s}}{\partial r}\right|_{r=0}=0
$$

at $r=0$ and:

$$
\left.D_{s} \frac{\partial c_{s}}{\partial r}\right|_{r=R_{s}}=-\frac{j^{\mathrm{Li}}}{a_{s_{n}} F}
$$

$$
\left.D_{s} \frac{\partial c_{s}}{\partial r}\right|_{r=R_{s}}=-\frac{j^{\mathrm{Li}}}{a_{s_{p}} F}
$$

respectively for negative and positive electrode. In Equations $(12,13), a_{s_{n}}$ and $a_{s_{p}}$ are the active surface area unit volume for, respectively, negative and positive electrode and:

$$
j^{\mathrm{Li}}=a_{s} i_{0}\left(\exp \left(\frac{\alpha_{o x} n F}{R_{g} T} \eta\right)-\exp \left(-\frac{\alpha_{\text {red }} n F}{R_{g} T} \eta\right)\right)
$$

where $a_{s}$ is chosen accordingly to the corresponding electrode. Using the Laplace transform to compute a diffusion impedance [44], it can be shown that in the limit of lowfrequencies and under the assumption of weak diffusion (i.e. $D_{s} \rightarrow \infty$ ) Equation (10), with the boundary conditions (11-13), is simplified in:

$$
\frac{d c_{s, n}}{d t}=-\frac{3}{a_{s, n} F R_{g}} j^{\mathrm{Li}}(t)
$$


for the negative electrode and:

$$
\frac{d c_{s, p}}{d t}=-\frac{3}{a_{s, p} F R_{g}} j^{\mathrm{Li}}(t)
$$

for the positive electrode. Equations $(15,16)$ are the basis of 0D (lumped parameters) models [45,46]. It is to be highlighted that, neglecting some dimensions, the $1 \mathrm{D}$ and the OD models suffer, as the equivalent circuit models, from a lack of precision for high current pulses. To evaluate the models, the only available experimental measures are the current and the voltage but not the SOC. Indeed, the direct active material measurement is still unavailable in automotive real time applications, in spite of the research efforts and a recent proposition for a promising technique for in situ quantification of the lithium concentration across battery electrodes [47]. As a consequence, the SOC computed with estimators can only be compared to the model SOC. In other words, the precision of the model with respect to the experiments also gives the precision of the frame in which the SOC estimation precision is evaluated. Rigorously, the accuracy of the cell charge level estimation should be evaluated by combining the effect of the estimation error with respect to the reference (i.e. the model), the accuracy of the reference with respect to the data and the confidence degree put in the model for predicting the solid active material evolution.

An exhaustive analysis can for example be found in $[2,10]$, showing that a SOC estimator based on a model validated against experimental voltage data with an average error of $28 \mathrm{mV}$ can reach a precision of 2-3\% with respect to the model prediction. It is also shown that the SOC estimation error drastically increases with the modeling error because the estimator modifies the SOC to compensate for the prediction error. This result is quite similar to the one obtained for the equivalent circuit model-based estimators, showing that the link between voltage and SOC intrinsically suffers from a lack of robustness.

\section{SUMMARY}

Table 1 summarizes the discussion and the results presented in the above sections. It shows that the precision of the model increases with its mathematical complexity and with its number of parameters. But increasing the number of parameters also increases the experimental efforts for their identification. In particular, the electrochemical models contain parameters related to the geometrical and physico-chemical properties of the materials composing the cell. Their identification requires specific tests, such as single-electrode analysis, that require the cell disassembling. This is not always possible because the manufacturers may impose restrictions on the cell usage.

When based on the input/output experimental data, the model identification is moderately difficult for the equivalent circuit but it suffers from a low sensitivity and hence a low robustness for the electrochemical models. Conversely, when detailed measurements are allowed, an electrochemical model exhibits certain advantages such as the physical meaning of SOC (it is related to the solid concentrations), a good precision, the prediction of both the solid and the electrolytic diffusion and their impact on the cell overvoltage, and the possibility of a coherent and appropriate integration of ageing effects leading to a good State of Health $(\mathrm{SOH})$ estimation.

TABLE 1

Batteries modeling

\begin{tabular}{c|c|c|c|c|c}
\hline Model & $\begin{array}{c}\text { Mathematical } \\
\text { complexity }\end{array}$ & Identification & $\begin{array}{c}\text { Required test } \\
\text { for identification }\end{array}$ & Precision & Applications \\
\hline $\begin{array}{c}\text { Ah-counting } \\
+ \text { OCV }\end{array}$ & Very low & Basic & $\begin{array}{c}\text { I/O } \\
\text { measurements }\end{array}$ & Poor & $\begin{array}{c}\text { SOC estimation, } \\
\text { cell balancing }\end{array}$ \\
\hline $\begin{array}{c}\text { Equivalent } \\
\text { circuit }\end{array}$ & Medium & Easy/ & EIS & Good & $\begin{array}{r}\text { Pack design, thermal management, } \\
\text { SOC and power estimation cell balancing, } \\
\text { vehicle energy management, } \\
\text { charge management }\end{array}$ \\
\hline $\begin{array}{c}\text { Electrochemical } \\
\text { OD }\end{array}$ & Medium-high & Difficult & $\begin{array}{c}\text { Multi-level } \\
\text { single-electrode }\end{array}$ & Good & $\begin{array}{c}\text { Pack design, thermal management, } \\
\text { SOC, SOH and power estimation, } \\
\text { cell balancing, vehicle energy management, } \\
\text { charge management }\end{array}$ \\
\hline $\begin{array}{c}\text { Electrochemical } \\
\text { 1D - pseudo2D }\end{array}$ & High & Difficult & $\begin{array}{c}\text { Multi-level } \\
\text { single-electrode }\end{array}$ & Good/high & $\begin{array}{c}\text { Pack design, thermal management } \\
\text { SOC, SOH and power estimation, } \\
\text { cell balancing, vehicle energy management, } \\
\text { charge, fast-charging management }\end{array}$ \\
\hline
\end{tabular}




\section{A CASE STUDY}

In this section, a case study of an impedance modelbased BMS application is presented. An equivalent circuit model was chosen because of the limitations to experiments imposed by the cell manufacturer. A semi-automatic procedure has been developed at IFP Energies nouvelles to obtain a coherent EIS based model.

Experimental spectroscopy data are first collected, covering a large range of SOC and temperatures. A current excitation waveform is applied to the system and the system's voltage response is monitored. All EIS measurements are done in a galvanostatic mode at open circuit, permitting, at the same time, the open circuit voltage characterization. The current amplitude is adapted to obtain a potential amplitude response under $10 \mathrm{mV}$, while the wave signal frequency varies between $10 \mathrm{kHz}$ and $5 \mathrm{mHz}$. Current amplitude and the stationarity of the response signal are controlled using an oscilloscope. For given SOC and temperature, an impedance diagram collects the wave response at different frequencies, in terms of real and imaginary part of the system frequency response. The diagrams are analyzed and an appropriate electric circuit is selected in order to reproduce the experimental spectra. All the parameters of the equivalent electric circuit are then automatically fitted from the data, as a function of SOC and temperature. In order to design the BMS, a time-domain model is required. Based on the range of frequencies and on the impedance electric equivalent elements, specific techniques have been elaborated to approximate the frequency-domain element with a resistor-capacitance network.

This procedure has been applied to a $22 \mathrm{Ah} \mathrm{NCA/graphite}$ $\mathrm{Li}$-ion cell in the framework of the collaborative project HYDOLE, led by PSA Peugeot Citroën and funded by the Agence de l'Environnement et de la Maîtrise de l'Energie (ADEME). For this specific case, the selected frequencydomain model is:

$$
Z(s)=R_{0}+\frac{R_{c t}}{1+R_{c t} C_{d l} s}+\frac{1}{Q s^{\alpha}}
$$

As an example, the experimental spectra are compared to the fitted frequency domain model in Figures 2, 3 for two couples of values of SOC and temperature.

The transposition to the time-domain model can be performed by means of the fractional impedance representation method [48]. The CPE impedance is approximated by a series of five resistor-capacitance circuits whose characteristic times are computed in order to ensure a satisfying accuracy in the limited frequency band $\left[\omega_{\min }, \omega_{\max }\right]$ corresponding to experimental frequencies range $[25,49]$, i.e., for this application, from $5 \mathrm{mHz}$ to $10 \mathrm{kHz}$. Thus, the resulting time-domain equivalent circuit model consists of an ohmic resistor, a medium frequencies charge transfer resistorcapacitance element and five resistor-capacitance elements

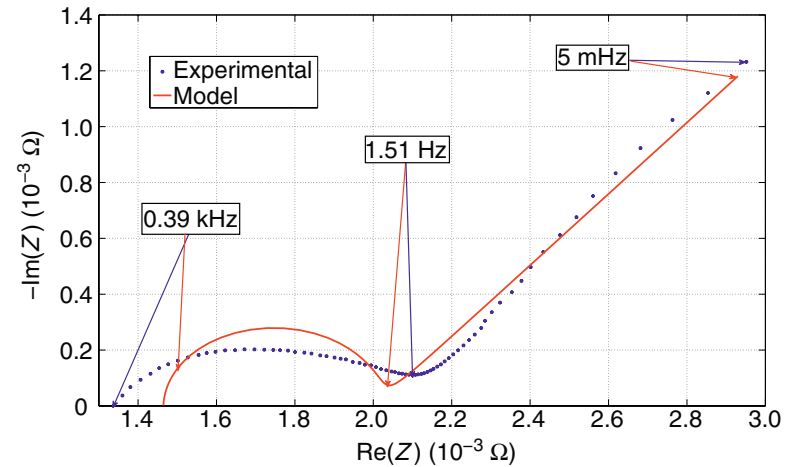

Figure 2

Experimental EIS data at SOC $=0.53$ and $T=293 \mathrm{~K} \mathrm{com}-$ pared to the frequency domain model.

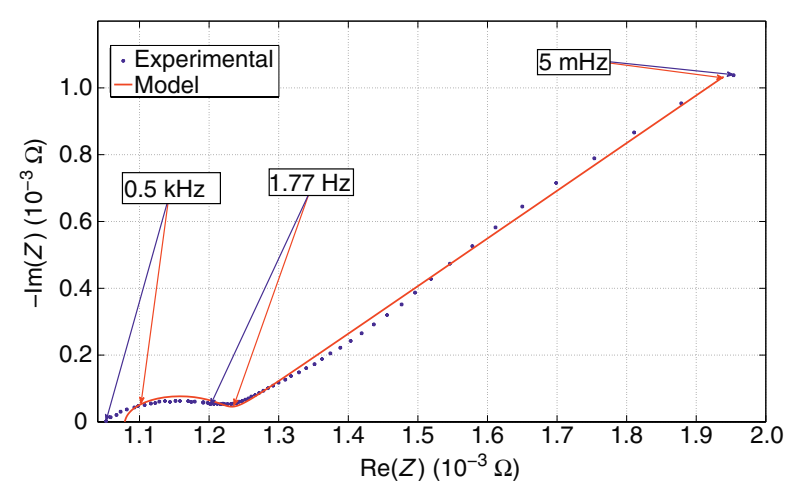

Figure 3

Experimental EIS data at SOC $=0.37$ and $T=313 \mathrm{~K} \mathrm{com}-$ pared to the frequency domain model.

approximating the low frequencies diffusion effects. A statespace formulation of the model can be expressed as:

$$
\left\{\begin{array}{l}
\dot{q}=\frac{1}{C_{\text {nom }}} I_{\text {cell }} \\
\dot{V}_{1}=\frac{1}{C_{d l}}\left(I_{\text {cell }}-\frac{V_{1}}{R_{c t}}\right) \\
\dot{V}_{d_{1}}=\frac{1}{C_{d_{1}}}\left(I_{\text {cell }}-\frac{V_{d_{1}}}{R_{d_{1}}}\right) \\
\dot{V}_{d_{2}}=\frac{1}{C_{d_{2}}}\left(I_{\text {cell }}-\frac{V_{d_{2}}}{R_{d_{2}}}\right) \\
\dot{V}_{d_{3}}=\frac{1}{C_{d_{3}}}\left(I_{\text {cell }}-\frac{V_{d_{3}}}{R_{d_{3}}}\right) \\
\dot{V}_{d_{4}}=\frac{1}{C_{d_{4}}}\left(I_{\text {cell }}-\frac{V_{d_{4}}}{R_{d_{4}}}\right) \\
\dot{V}_{d_{5}}=\frac{1}{C_{d_{5}}}\left(I_{\text {cell }}-\frac{V_{d_{5}}}{R_{d_{5}}}\right)
\end{array}\right.
$$

where $R_{d_{i}}$ and $C_{d_{i}}$ are the parameters of the resistorcapacitance elements approximating the low frequencies 


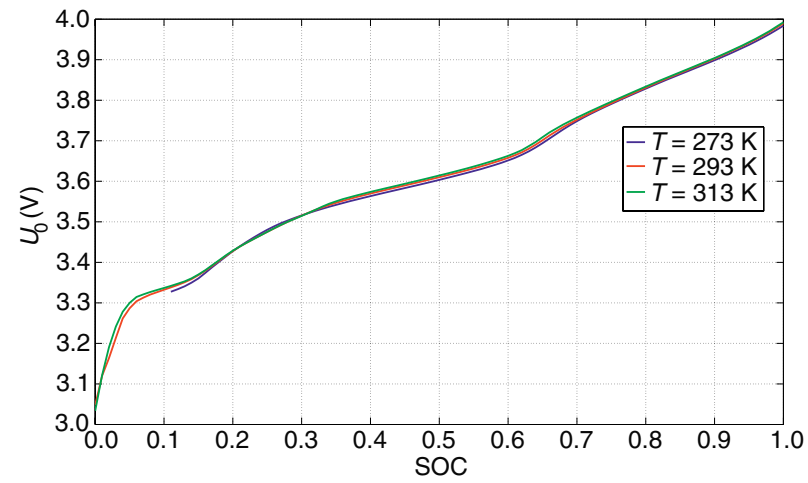

Figure 4

Cell open circuit voltage, as a function of SOC and temperature.

diffusion effects. Finally the cell voltage is computed as:

$$
V=U_{0}+R_{0} I_{c e l l}+V_{1}+\sum_{i=1}^{5} V_{d_{i}}
$$

where all the parameters are function of SOC and temperature and $U_{0}$ is the open circuit voltage, obtained during the cell characterization procedure and shown in Figure 4 for some temperatures.

Figures 5, 6 show the performance of the model. Two cycles were considered. The first one, in Figure 5, reproduces a typical automotive usage of a cell on an urban/extraurban driving cycle. The initial cell temperature was set to $298 \mathrm{~K}$. The test in Figure 6 is a 1C rate charge/discharge cycle with the cell temperature regulated at $292 \mathrm{~K}$. It can be noted that the average prediction error is less than $20 \mathrm{mV}$. Based on the discretized version of this model an Extended Kalman Filter (EKF) was designed to estimate the SOC and cell overvoltages, according to:

$$
\left\{\begin{array}{l}
\hat{x}(k \mid k)=\hat{x}(k \mid k-1)+T_{e} f(\hat{x}(k \mid k-1), u(k))+K_{e}(k) e(k) \\
\hat{y}(k \mid k-1)=V(\hat{x}(k \mid k-1), u(k))
\end{array}\right.
$$

where $\hat{x}$ and $\hat{y}$ are respectively the estimated state and output, $T_{e}$ is the sampling period, $e(k)$ is the prediction error computed as:

$$
e(k)=(y(k)-\hat{y}(k \mid k-1))
$$

$f(\cdot)$ is the nonlinear function deduced from (18) and $V(\cdot)$ is the nonlinear output function (19). The notation $\mathfrak{F}(k \mid k-1)$ indicates the a priori predicted variable $\mathfrak{F}$ value and $\mathfrak{F}(k \mid k)$ the a posteriori updated variable $\mathfrak{F}$ value. $K_{e}(k)$ is the Kalman gain, obtained through:

$$
K_{e}(k)=\Sigma(k \mid k-1)-\Sigma(k \mid k-1) C(k) \Omega(k) C^{T}(k) \Sigma(k \mid k-1)
$$

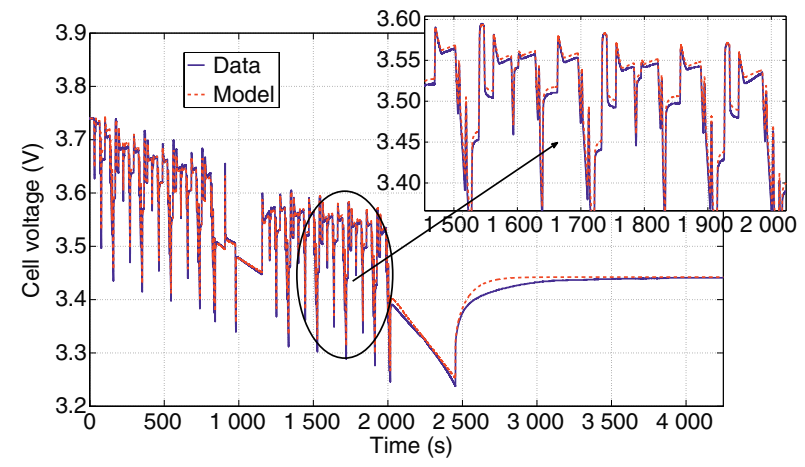

Figure 5

Cell voltage compared to the Lithium-ion cell model prediction during an urban/extra-urban driving cycle.

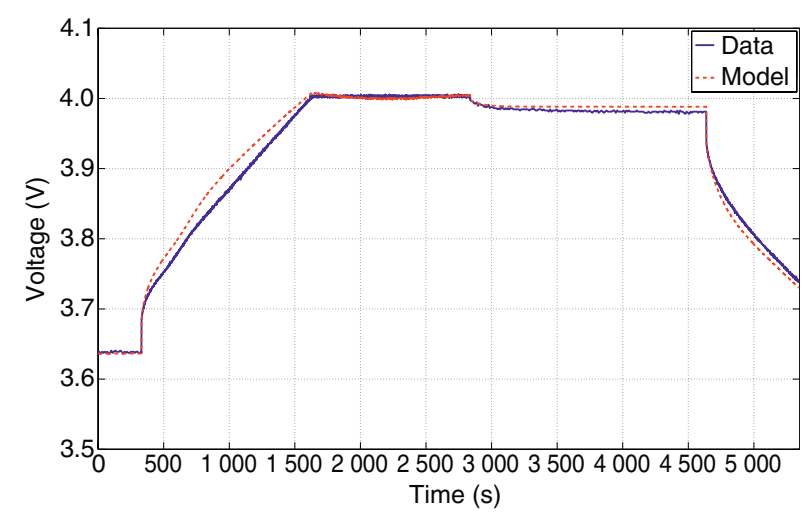

Figure 6

Cell voltage compared to the Lithium-ion model prediction during a charge-discharge of the cell.

$$
\begin{aligned}
& \Omega(k)=\left[C(k) \Sigma(k \mid k-1) C^{T}(k)+R\right]^{-1} \\
& \Sigma(k+1 \mid k)=\gamma^{2} F(k) \Sigma(k \mid k) F^{T}(k)+Q
\end{aligned}
$$

where $\Sigma$, the solution of the Riccati equation, is the covariance matrix of the state error, $\gamma$ is the forgetting factor, varying between 0 and $1, F(k)$ is the dynamic matrix of the linearized system, $Q$ and $R$ are the process and measurements noises covariance matrices. As the model uncertainties and the measurement noise are not known a priori, $Q$ and $R$ are appropriately tuned off-line to minimize the mean square error on the SOC. The estimation algorithm performance is shown in Figures 7, 8. Figure 7 compares the SOC estimation to an Ah counting correctly initialized, as the SOC measurement is unavailable. As shown, the EKF is able to recover the error of $35 \%$ in the initial conditions, then to maintain the error in a limited band of $\pm 2 \%$. At the same time, the EKF is also able to estimate the other state components, i.e. the charge transfer and the diffusion overpotentials. As an example the estimation of $V_{d_{1}}$ is compared to the correctly initialized model prediction in Figure 8. 


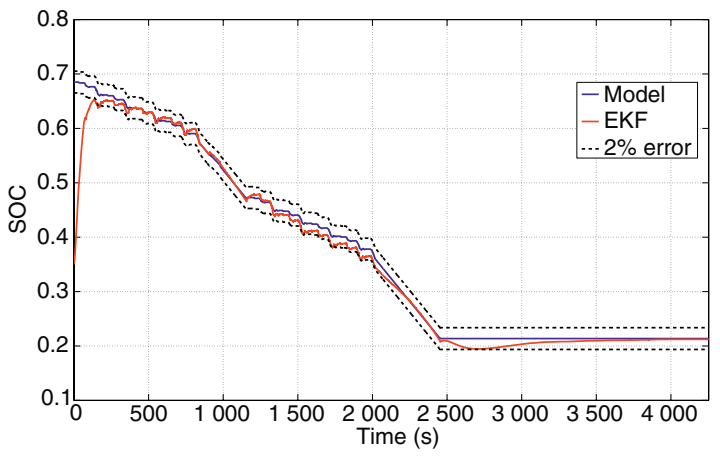

Figure 7

SOC estimation result during an urban/extra-urban driving cycle test.

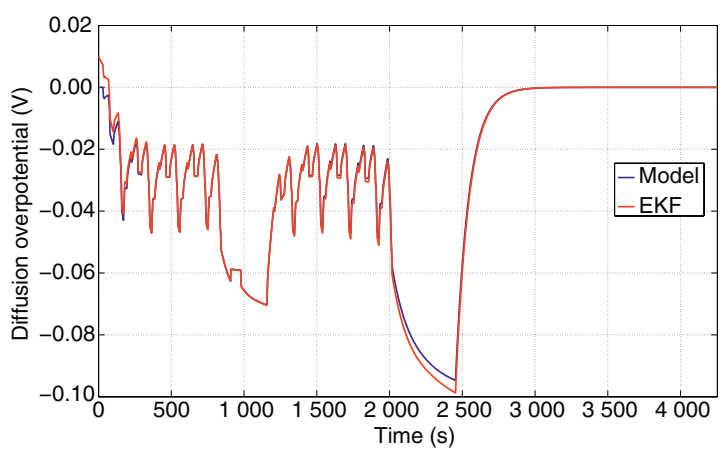

Figure 8

Diffusion overpotential estimation result during an urban/extra-urban driving cycle test.

\section{CONCLUSION}

A short review of the main modeling techniques for the design of BMS for automotive application has been presented. Ah counting, circuit equivalent model-based and electrochemical model-based SOC observers have been considered, highlighting the impact of the cell model precision and complexity on the estimator performance. The main advantages as well as the critical points have been discussed. A case-test has been proposed to show the performance of a complete procedure for the SOC estimator design, from the cell characterization to the online experimental test. The test includes several operating conditions. The results of the experimental tests based on the data collected on batteries testing facilities of IFP Energies nouvelles show that the proposed procedure allows for a satisfying state of charge real time estimation, with an error of about $2 \%$.

\section{ACKNOWLEDGMENTS}

The authors gratefully acknowledge funding provided by the Agence de l'Environnement et de la Maîtrise de l'Énergie (CF n. 0966C0142). Special thanks also go to Guillaume
Chérouvrier (PSA Peugeot Citroën) who leads the R\&D activities related to the batteries for the HYDOLE project.

\section{REFERENCES}

$1 \mathrm{Hu}$ Y., Yurkovich S., Guezennec Y., Yurkovich B. (2011) Electro-thermal battery model identification for automotive applications. J. Power Sources 196, 449-457.

2 Chaturvedi N., Klein R., Christensen J., Ahmed J., Kojic A. (2010) Algorithms for advanced battery-management systems, IEEE Control Syst. Mag. 30, 49-68.

3 Wang J., Guo J., Ding L. (2009) An adaptive Kalman filtering based state of charge combined estimator for electric vehicle battery pack, Energy Conver. Manage. 50, 3182-3186.

4 Piller S., Perrin M., Jossen A. (2001) Methods for state-ofcharge determination and their applications, J. Power Sources 96, 113-120.

5 Lin C., Chen Q., Wang J. (2001) Improved Ah counting method for state of charge estimation of electric vehicle batteries, J. Tsinghua University Sci. Technol. 46, 247-251.

6 Terry H., Wang C. (2005) Support vector based battery state of charge estimator, J. Power Sources 141, 351-358.

7 Barbarisi O., Vasca F., Glielmo L. (2006) State of charge Kalman filter estimator for automotive batteries, Control Eng. Pract. 14, 267-275.

8 Di Domenico D., Fiengo G., Stefanopoulou A. (2008) Lithiumion battery state of charge estimation with a Kalman filter based on a electrochemical model, Proc. of 2008 IEEE International Conference on Control Applications, 3-5 Sept., 1, 702707.

9 Di Domenico D., Prada E., Creff Y. (2011) An adaptive strategy for Li-ion battery SOC estimation, Proceedings of 2011 IFAC World Congress, Milan, Italy, 28 Aug.-2 Sept., Vol. 3, Part. 1.

10 Kleinand R., Chaturvedi N., Christensen J., Ahmed J., Findeisen R., Kojic A. (2010) State estimation of a reduced electrochemical model of a lithium-ion battery, Proceedings of 2010 American Control Conference (ACC 2010), Baltimore, Maryland, 30 June-2 July, pp. 6618-6623.

11 Pang S., Farrell J., Du J., Barth M. (2001) Battery state-ofcharge estimation, Proceedings of the American Control Conference (ACC 2001), Arlington, Virginia, 25-27 June, Vol. 2, 1644-1649.

12 Plett G. (2004) Extended kalman filtering for battery management systems of LiPB-based HEV battery packs. Part 1. Background, J. Power Sources 134, 252-261.

13 Plett G. (2004) Extended kalman filtering for battery management systems of LiPB-based HEV battery packs. Part 2. Modeling and identification, J. Power Sources 134, 262-276.

14 Plett G. (2004) Extended Kalman filtering for battery management systems of LiPB-based HEV battery packs. Part 3. State and parameter estimation, J. Power Sources 134, 277-292.

15 Pop V., Bergveld H.J., Op het Veld J.H.G., Regtien P.P.L., Danilov D., Notten P.H.L. (2006) Modeling battery behavior for accurate state-of-charge indication. J. Electrochem. Soc. 153, A2013-A2022.

16 Santhanagopalan S., White R. (2006) Online estimation of the state of charge of a lithium ion cell, J. Power Sources 161, 1346-1355.

17 Santhanagopalan S., White R. (2010) State of charge estimation using an unscented filter for high power lithium ion cells, Int. J. Energy Res. 34, 152-163. 
18 Smith K., Rahn C., Wang C. (2008) Model-based electrochemical estimation of lithium-ion batteries, Proceedings of 2008 IEEE International Conference on Control Applications (CCA 2008), San Antonio, Texas, 3-5 Sept., pp. 714-719.

19 Verbrugge M., Tate E. (2004) Adaptive state of charge algorithm for nickel metal hydride batteries including hysteresis phenomena, J. Power Sources 126, 236-249.

20 Kong Soon Ng, Chin-Sien Moo, Yi-Ping Chen, Yao-Ching Hsieh (2009) Enhanced Coulomb counting method for estimating state-of-charge and state-of-health of lithium-ion batteries, Appl. Energy 86, 1506-1511.

21 Mauracher P., Karden E. (1997) Dynamic modelling of lead/acid batteries using impedance spectroscopy for parameter identification, J. Power Sources 67, 69-84.

22 Diard J.P., Le Gorrec B., Montella C. (1996) Cinétique électrochimique, Hermann, Paris.

23 Cole K.S., Cole R.H. (1941) Dispersion and absorption in dielectrics I. alternating current characteristics, J. Chem. Phys. 9, 4, 341-351.

24 Andre D., Meilera M., Steinera K., Walza H., Soczka-Gutha T., Sauer D. (2011) Characterization of high-power lithium-ion batteries by electrochemical impedance spectroscopy. II. Modelling, J. Power Sources 196, 5349-5356.

25 Montaru M., Pelissier S. (2010) Frequency and temporal identification of a li-ion polymer battery model using fractional impedance, Oil Gas Sci. Technol. - Rev. IFP 65, 67-78.

26 Kuhn E., Forgez C., Lagonotte P., Friedrich G. (2006) Modelling NiMH battery using Cauer and Foster structures. J. Power Sources 158, 1490-1497.

27 Gould C.R., Bingham C.M., Stone D.A., Bentley P. (2009) New battery model and state-of-health determination through subspace parameter estimation and state-observer techniques, IEEE Trans. Vehic. Technol. 58, 3905-3916.

28 Stuart T., Fang F., Wang X., Ashtiani C., Pesaran A. (2002) A modular battery management system for HEVs, Proceedings of the SAE Future Car Congress, SAE Technical Paper 200201-1918.

29 Verbrugge M.W., Conell R.S. (2002) Electrochemical and thermal characterization of battery modules commensurate with electric vehicle integration, J. Electrochem. Soc. 149, 1, A45-A53.

30 Verbrugge M.W., Conell R.S. (2007) Electrochemical characterization of high-power lithium ion batteries using triangular voltage and current excitation sources, J. Power Sources 174, 2-8.

$31 \mathrm{Hu}$ T., Zanchi B., Zhao J. (2011) Simple analytical method for determining parameters of discharging batteries, IEEE Trans. Energy Conver. 26(3), 787-798.

32 Plett G. (2006) Sigma-point Kalman filtering for battery management systems of LiPB-based HEV battery packs: Part 1: Introduction and state estimation, J. Power Sources 161, 1356-1368.

33 Plett G. (2005) Results of temperature-dependent LiPB cell modeling for HEV SOC estimation, Proceedings of the 21st Electric Vehicle Symposium, Monaco, 2-6 April.
34 Newman J., Tiedemann W. (1975) Porous-electrode theory with battery applications, AIChE J. 21, 25-41.

35 Wang C., Gu W., Liaw B. (1998) Micro-macroscopic coupled modeling of batteries and fuel cells. Part I. Model development, J. Electrochem. Soc. 145, 3407-3417.

36 Wang C., Gu W., Liaw B. (1998) Micro-macroscopic coupled modeling of batteries and fuel cells. Part II. Application to nickel-cadmium and nickel-metal hydride cells, J. Electrochem. Soc. 145, 3418-3427.

37 Gu W., Wang C. (2000) Thermal and electrochemical coupled modeling of a lithium-ion cell, Proc. ECS 99-25, 748-762.

38 Smith K., Wang C. (2006) Solid-state diffusion limitations on pulse operation of a lithium-ion cell for hybrid electric vehicles, J. Power Sources 161, 628-639.

39 Ramadass P., Haran B., Gomadam P., White R., Popov B. (2004) Development of first principles capacity fade model for li-ion cells, J. Electrochem. Soc. 151, A196-A203.

40 Weidner J.W., Timmerman P. (1994) Effect of proton diffusion, electron conductivity, and charge-transfer resistance on nickel hydroxide discharge curves, J. Electrochem. Soc. 141, 346-351.

41 Haran B., Popov B., White R. (1998) Determination of the hydrogen diffusion coefficient in metal hydrides by impedance spectroscopy. J. Power Sources 75, 56-63.

42 Di Domenico D., Stefanopoulou A., Fiengo G. (2010) Lithiumion battery state of charge and critical surface charge estimation using an electrochemical model-based extended kalman filter, J. Dyn. Syst. Meas. Control 132, 6, 61302-61313.

43 Santhanagopalan S., Guo Q., Ramadass P., White R. (2006) Review of models for predicting the cycling performance of lithium-ion batteries, J. Power Sources 156, 620-628.

44 Jacobsen T., West K. (1995) Diffusion impedance in planar, cylindrical and spherical symmetry, Electrochimica Acta 40, 2, 255-262, ISSN 0013-4686.

45 Bernard J., Sciarretta A., Touzani Y., Sauvant-Moynot V. (2010) Advances in electrochemical models for predicting the cycling performance of traction batteries: Experimental study on NiMH and simulation, Oil Gas Sci. Technol. - Rev. IFP 65 , 55-66.

46 Wu B., Mohammed M., Brigham D., Elder R., White R. (2001) A non-isothermal model of a nickel-metal hydride cell, J. Power Sources 101, 149-157.

47 Siegel J.B., Lin X., Stefanopoulou A., Hussey D.S., Jacobson D.L., Gorsich D. (2011) Neutron imaging of lithium concentration in LFP pouch cell battery, J. Electrochem. Soc. 158, A523-A529.

48 Oustaloup A., Cois O., Le Lay L. (2005) Représentation et identification par modèle non entier, Lavoisier, Paris.

49 Sabatier J., Aoun M., Oustaloup A., Grègoire G., Ragot F., Roy P. (2006) Fractional system identification for lead acid battery state of charge estimation, Signal Process 86, 2645-2657.

Final manuscript received in September 2012 Published online in February 2013

Copyright $\odot 2013$ IFP Energies nouvelles

Permission to make digital or hard copies of part or all of this work for personal or classroom use is granted without fee provided that copies are not made or distributed for profit or commercial advantage and that copies bear this notice and the full citation on the first page. Copyrights for components of this work owned by others than IFP Energies nouvelles must be honored. Abstracting with credit is permitted. To copy otherwise, to republish, to post on servers, or to redistribute to lists, requires prior specific permission and/or a fee: Request permission from Information Mission, IFP Energies nouvelles, fax. +331475270 96, or revueogst@ifpen.fr. 